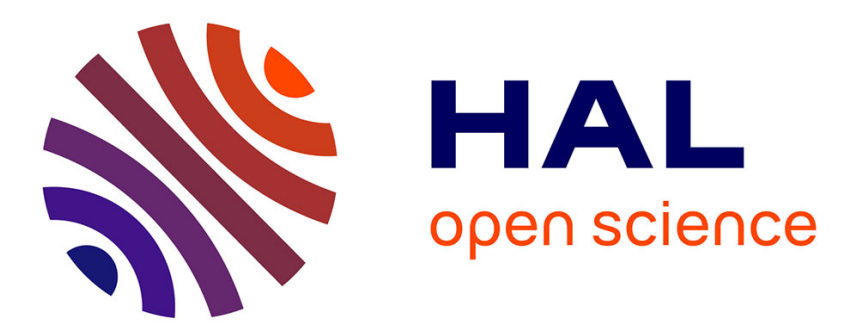

\title{
Combustion state monitoring of premixed heating appliances with flame ionization current and chemiluminescence
}

\author{
Yi Ding, Daniel Durox, Nasser Darabiha, Thierry Schuller
}

\section{To cite this version:}

Yi Ding, Daniel Durox, Nasser Darabiha, Thierry Schuller. Combustion state monitoring of premixed heating appliances with flame ionization current and chemiluminescence. Combustion Science and Technology, In press, 10.1080/00102202.2018.1472085 • hal-01835885

\section{HAL Id: hal-01835885 \\ https://hal.science/hal-01835885}

Submitted on $30 \mathrm{Jul} 2018$

HAL is a multi-disciplinary open access archive for the deposit and dissemination of scientific research documents, whether they are published or not. The documents may come from teaching and research institutions in France or abroad, or from public or private research centers.
L'archive ouverte pluridisciplinaire HAL, est destinée au dépôt et à la diffusion de documents scientifiques de niveau recherche, publiés ou non, émanant des établissements d'enseignement et de recherche français ou étrangers, des laboratoires publics ou privés. 


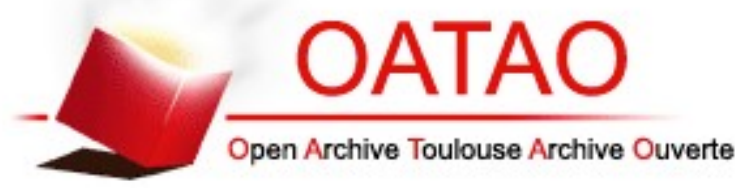

\section{Open Archive Toulouse Archive Ouverte}

OATAO is an open access repository that collects the work of Toulouse researchers and makes it freely available over the web where possible

This is an author's version published in: http://oatao.univ-toulouse. $f r / n^{\circ} 20243$

\section{Official URL:}

http://dx.doi.org/10.1016/j.ecolind.2013.09.001

\section{To cite this version:}

Ding, Yi and Durox, Daniel and Darabiha, Nasser and Schuller, Thierry Combustion state monitoring of premixed heating appliances with flame ionization current and chemiluminescence. (2018) Combustion Science and Technology, 20. pp. 1-20. ISSN 0010-2202

Any correspondence concerning this service should be sent to the repository administrator: tech-oatao@listes-diff.inp-toulouse.fr 


\title{
Combustion state monitoring of premixed heating appliances with flame ionization current and chemiluminescence
}

\author{
Yi Ding a,b, Daniel Durox ${ }^{a}$, Nasser Darabihaa, and Thierry Schuller ${ }^{a, c}$ \\ aLaboratoire EM2C, CNRS, CentraleSupélec, Université Paris Saclay, Gif-sur-Yvette, France; ${ }^{b}$ Bosch \\ Thermotechnologie, Saint-Thégonnec, France; Institut de Mécanique des Fluides de Toulouse (IMFT), \\ Université de Toulouses, CNRS, Toulouse, France
}

\begin{abstract}
The development of a combustion operating point control system has received interests from gas boiler manufacturers in order to ensure optimized performances despite variations of natural gas composition. Fully premixed burners are widely used in these boilers and the equivalence ratio is a key parameter to control. Experiments are carried out in this study for $\mathrm{CH}_{4} /$ air fuel blends diluted by $\mathrm{N}_{2}$ or $\mathrm{CO}_{2}$ or enriched by $\mathrm{H}_{2}, \mathrm{C}_{2} \mathrm{H}_{6}$, or $\mathrm{C}_{3} \mathrm{H}_{8}$. Two low cost solutions for monitoring the equivalence ratio based on the flame ionization current and the chemiluminescence signal are investigated on a laboratory laminar conical flame. The behavior of the ionization current with changes of gas velocity, fuel composition, and equivalence ratio is shown to be mainly related to the size of the dead space between the flame base and burner rim. In a second stage, changes of the chemiluminescence signal is studied and the use of $\mathrm{CH}^{*} / \mathrm{OH}^{*}$ intensity ratio as an equivalence ratio indicator is verified. Numerical 1-D premixed flame simulations are performed to support the experimental results on the flame chemiluminescence. Finally, a third equivalence ratio sensing method is proposed, coupling both techniques and the three strategies are compared.
\end{abstract}

\section{KEYWORDS}

Combustion control; Domestic boiler; Flame ionization current; Flame chemiluminescence

\section{Introduction}

Due to a decreasing indigenous natural gas supply, the European gas network is expecting a more diverse set of supply sources (Williams et al., 2012), which may also lead to larger variations of the gas composition in a near future. In addition, the injection of gases from renewable resources (e.g. biogas and hydrogen) in the gas network may introduce new gas components. These evolutions set a challenge for domestic gas boiler manufacturers, who must ensure an optimized performance of their apparatus despite the composition variations of gas supply.

Perfectly premixed burners are widely used in modern domestic gas boilers. The mixture equivalence ratio must be maintained within an optimized range to achieve low pollutant emissions and high efficiency (Docquier and Candel, 2002). The current control strategy based on a fixed fuel composition needs to be reconsidered in view of the future gas composition variations.

CONTACT Yi Ding $\otimes$ yi.ding.chn@gmail.com $\Theta$ Laboratoire EM2C, CNRS, CentraleSupélec, Université Paris Saclay, 3 rue Joliot Curie, Gif-sur-Yvette 91192, France. 
The development of an automatic combustion control system, capable of regulating the operating point according to the changes of the fuel blend composition, has therefore received interests from the manufacturers (Näslund, 2014). For this purpose, the first step is to gain reliable and precise information on the combustion state. An extensive review of potential techniques and sensors has been performed by Docquier and Candel (2002). Considering the strict requirements on the cost and simplicity of the technological control solution set by the market of household gas boilers, the present study focuses on two lowcost solutions allowing to monitor the equivalence ratio of perfectly premixed flames. The signals originating from the ionization current and flame chemiluminescence are both explored to this purpose.

The flame ionization current can be measured when a bias voltage is applied between an ionization probe and the metallic burner surface. Its intensity is known to be related to the flame equivalence ratio and flame monitoring systems based on this technique are emerging in recent years (Kiefer et al., 2012; Näslund, 2014). The flame conductivity is achieved, thanks to the ions and electrons produced during the combustion process (Calcote, 1961; Fialkov, 1997). For a lean methane-air flame, the main charge carriers include $\mathrm{H}_{3} \mathrm{O}^{+}, \mathrm{O}_{2}^{-}$, and electrons. Many studies were conducted in internal combustion engines. Franke (2002) and Rodrigues (2005) revealed that the surface area of the cathode is essential to achieve a strong current intensity. Analytical models derived by Rodrigues (2005) and Karrer et al. (2010) reveal that the ionization current intensity is linked to with the flame quenching distance. Fewer studies are found for applications in domestic gas boilers. Kiefer et al. (2012) measured the ionization current on a real gas boiler and found that the current intensity depends on the gas velocity. Nevertheless, a more comprehensive investigation on the effects of many factors like the power, gas composition, probe position, etc. is still needed for the design of a flame monitoring system.

An alternative technique concerns the flame chemiluminescence, which is easy to record and sensitive to the equivalence ratio. The diagnostic technique is mainly based on the emission intensities of $\mathrm{OH}^{*}$ at $308 \mathrm{~nm}, \mathrm{CH}^{*}$ at $430 \mathrm{~nm}, \mathrm{C}_{2}{ }^{*}$ at $516 \mathrm{~nm}$ and $\mathrm{CO}_{2}{ }^{*}$ between 300 and $600 \mathrm{~nm}$, often represented by the intensity at $450 \mathrm{~nm}$. Its application to real combustion systems has recently been reviewed by Ballester and García-Armingol (2010). Docquier et al. (2002) have developed a demonstrative equivalence ratio controller for a conical methane-air flame, based on a lookup table consisting of two intensity ratios $\mathrm{OH}^{*} / \mathrm{CH}^{*}$ and $\mathrm{CO}_{2}^{*} / \mathrm{CH}^{*}$. The ratio of two emission intensities, initially proposed in Kojima et al. (2000), is commonly used in later studies to remove the impact of disturbing factors like the power, strain rate, and optical obstructions. Effects of the fuel type were also investigated. Orain and Hardalupas (2010) studied the chemiluminescence of different fuels and found that the response of the $\mathrm{OH}^{\star} / \mathrm{CH}^{\star}$ intensity ratio vs. equivalence ratio depends on the fuel nature. Studies with fuel blends are relatively few. García-Armingol and Ballester (2014a, 2014b) studied emissions of $\mathrm{CH}_{4} / \mathrm{CO}_{2} / \mathrm{H}_{2} / \mathrm{CO}$ flames. They found that the intensity ratio $\mathrm{OH}^{\star} / \mathrm{CH}^{*}$ could be applicable to detect the equivalence ratio of fuels diluted with different levels of $\mathrm{CO}_{2}$. When $\mathrm{H}_{2}$ is added to methane, the $\mathrm{OH}^{\star} / \mathrm{CH}^{*}$ signal shows a non-monotonic behavior for equivalence ratios $\phi>0.75$ and the $\mathrm{OH}^{\star} / \mathrm{CO}_{2}^{*}$ intensity ratio is a better alternative in this case. Guiberti et al. (2015) studied the impact of $\mathrm{N}_{2}$ and $\mathrm{CO}_{2}$ dilution on the chemiluminescence and found that they both reduce the 
chemiluminescence intensity of $\mathrm{CH}^{*}, \mathrm{OH}^{*}$, and $\mathrm{CO}_{2}^{*}$ per unit flame surface area, but $\mathrm{CO}_{2}$ yields a larger drop than $\mathrm{N}_{2}$ for the same molar fraction in the fuel blend.

Changes of the chemiluminescence intensity with equivalence ratio and inert gas dilution are attributed in some studies to the flame temperature. Lee and Santavicca (2003) argue that it is the flame temperature rather than the equivalence ratio by itself that changes the chemiluminescence intensity. One of the supports for this claim is the numerical results from Samaniego et al. (1995). For mixtures at different equivalence ratios and $\mathrm{N}_{2}$ dilutions, these authors found that the $\mathrm{CO}_{2}^{*}$ emission intensity per unit flame surface area is correlated to the burnt gas temperature.

Despite these investigations, there is yet no systematic analysis of effects of variations of the fuel gas composition on the equivalence ratio sensing either through the use of flame ionization current or flame chemiluminescence.

In the present study, a premixed conical flame setup is used as a generic system to investigate the flame ionization current and chemiluminescence signal and evaluate the possibilities to use these signals to combustion monitoring in domestic gas boilers. The first part of this study is dedicated to the flame ionization current. A series of tests are performed to understand the impact of probe position, flame power, and fuel composition. An explanation of these effects is then proposed by relating the current intensity with the size of dead space between the flame base and burner rim. The second part of this study focuses on the flame chemiluminescence with different natural gas compositions. Binary fuel blends are considered with $\mathrm{CH}_{4}$ and the five major secondary components, including $\mathrm{N}_{2}, \mathrm{CO}_{2}, \mathrm{H}_{2}, \mathrm{C}_{2} \mathrm{H}_{6}$, and $\mathrm{C}_{3} \mathrm{H}_{8}$. Their impact on the chemiluminescence emissions of $\mathrm{CH}^{*}, \mathrm{OH}^{*}$, and $\mathrm{CO}_{2}^{*}$ is studied and the response of the $\mathrm{CH}^{*} / \mathrm{OH}^{*}$ intensity ratio as a function of equivalence ratio is analyzed. In addition, direct numerical simulations with the REGATH code (Candel et al., 2011) are conducted to provide a support for the experimental results. It is finally discussed how to combine these signals to monitor the operating point of domestic boilers.

\section{Methodology}

\subsection{Burner and measurement facilities}

Experiments are performed with a conical flame burner, sketched in Figure 1. The fuel-air mixture is prepared in a cyclonic pot with three entries, attributed respectively to air, methane, and one secondary component investigated $\left(\mathrm{N}_{2}, \mathrm{CO}_{2}, \mathrm{H}_{2}, \mathrm{C}_{2} \mathrm{H}_{6}, \mathrm{C}_{3} \mathrm{H}_{8}\right)$. Each gas flowrate is controlled by a specific mass flowmeter. The fuel-air mixture exiting the pot is guided by two identical plastic ducts to the plenum. Inside the plenum, it passes first through a perforated plate conceived to homogenize the flow, then through a honeycomb structure helping to laminarize it, and right before the exit nozzle, a mesh-wire grid to prevent flashback and break the residual turbulent vortices. A converging nozzle, with a contraction ratio of 8.7 , guides the flow and the combustible mixture leaves the burner with a quasi-uniform top hat velocity profile. The nozzle outlet features a diameter of $22 \mathrm{~mm}$ and corresponds to the diameter of the base of the conical flame.

The configuration for ionization current mimics the case in a real gas boiler (see Figure 2a). An ionization probe is installed horizontally above the burner exit. The probe is a metallic cylindrical stick with a diameter of $2.5 \mathrm{~mm}$ and a total length of 


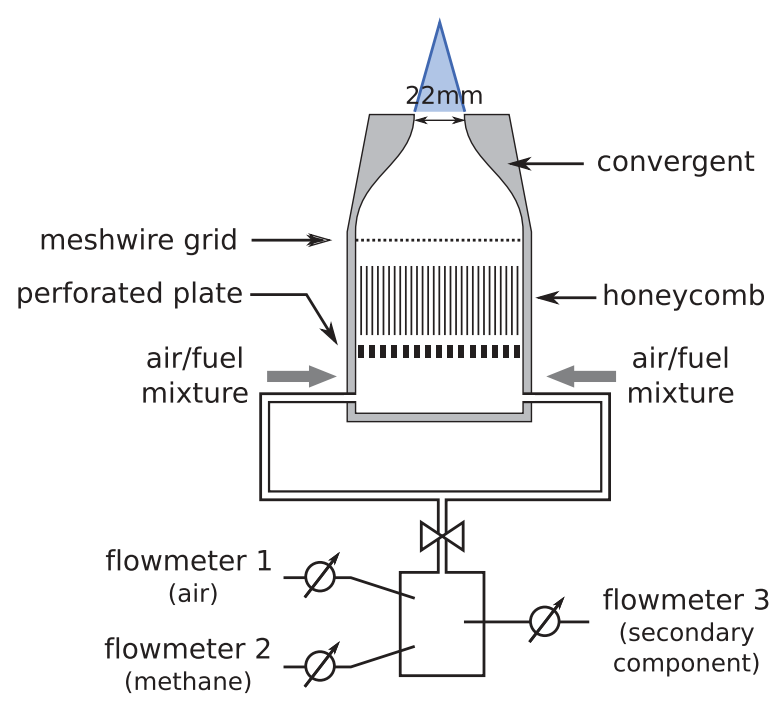

Figure 1. Conical flame burner.

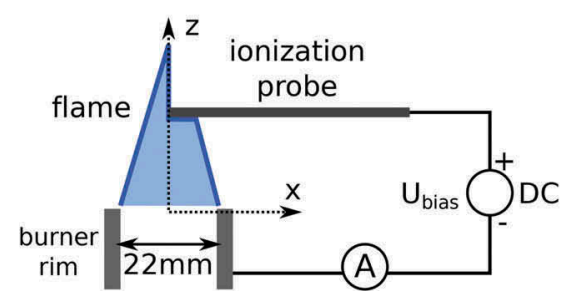

(a) Flame ionization current

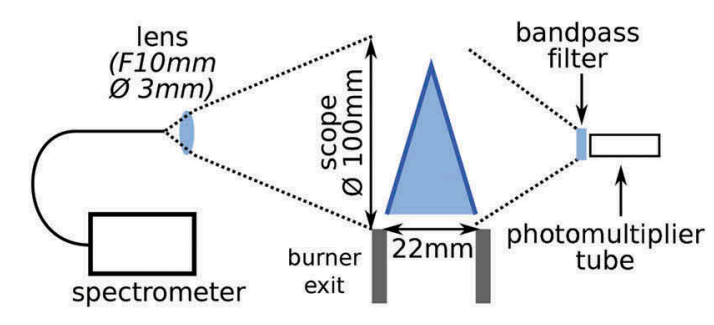

(b) Flame chemiluminescence

Figure 2. Measurement configurations.

about $20 \mathrm{~cm}$. The useful segment is the part in contact with the flame front or the burnt gases. The position of the probe is specified in the following by the coordinates $(x, z)$ of its tip as shown in Figure 2a. A DC voltage is applied between the probe and the metallic burner exit, and the former serves always as the anode. The current is measured with an ammeter. Once stabilized, current intensity fluctuations remain within $\pm 0.1 \mu \mathrm{A}$.

Effects of the gas velocity, equivalence ratio and fuel composition on the ionization current are investigated by relating the intensity to the stand-off distance between the flame and burner rim. This distance is measured with an ICCD camera (Princeton Instrument, PI-Max, $512 \times 512$ pixels) equipped with a Nikkor $105 \mathrm{~mm} \mathrm{F/2.8} \mathrm{lens.} \mathrm{The}$ setup allows to zoom in a tiny zone near the flame base as shown in Figure 3. The position of the flame base is determined based on a threshold of $25 \%$ of the maximum intensity. The uncertainty is estimated to be \pm 1 pixel or $\pm 0.03 \mathrm{~mm}$. Results were found to be weakly altered by the choice of the intensity threshold level when chosen between $15 \%$ and $40 \%$.

For chemiluminescence measurements with the setup shown in Figure 2b, the light emitted by the flame is collected by a lens $(F=10 \mathrm{~mm}, \phi=3 \mathrm{~mm})$ and guided by an optical 


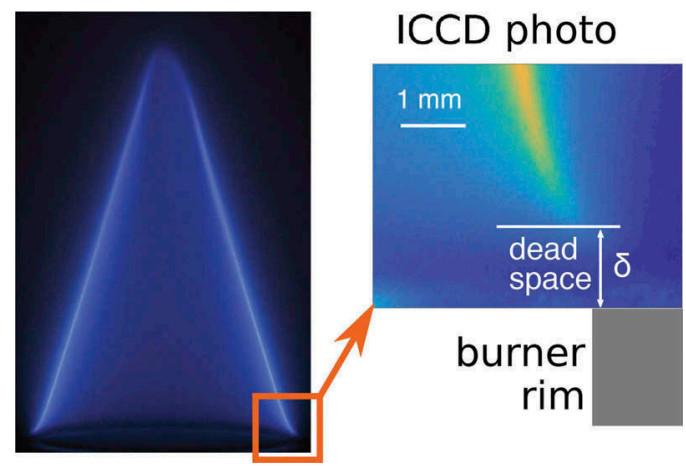

Figure 3. Dead space between flame base and burner rim.

fiber to a low resolution OceanOptics USB2000+ spectrometer (200-900 nm). The field of view covered by the optical setup is a circular area of about $100 \mathrm{~mm}$ diameter, which is larger than the longest flame explored during the study. $\mathrm{CH}^{\star}$ and $\mathrm{OH}^{\star}$ intensities are deduced from the recorded flame spectra by measuring the height of the emission peaks with respect to the baseline of the signal. This method allows to exclude the $\mathrm{CO}_{2}^{*}$ broadband emission and undesirable stray light signal. The $\mathrm{CO}_{2}^{*}$ intensity is determined with a photomultiplier tube (Hamamatsu H11902-110) mounted with a bandpass optical filter centered at $450 \mathrm{~nm}$ in order to avoid the possible interference with the stray light signal. The scope of the photomultiplier tube is also large enough to collect all the $\mathrm{CO}_{2}^{*}$ emissions from the flame.

One potential source of error with the optical setup shown in Figure $2 b$ is that the optical collection efficiency is not perfectly uniform over the interrogation area. It is found to drop slightly toward the border of the field of view. This mainly alters the signal recorded from elongated flames, for which part of the flame near the tip is located in a zone with a lower collecting efficiency. Nevertheless, the flame tip constitutes a relatively small fraction of the reaction layer and the resulting relative error is estimated to be less than a few percent.

\subsection{1-D freely propagating flame simulation}

In addition to the spectroscopic measurements, a numerical approach is adopted to study the impact of secondary components on the flame chemiluminescence, with a 1-D freely propagating flame model. Simulations are carried out with the REGATH code developed at EM2C laboratory (Candel et al., 2011). The simulations for the fuel blends of $\mathrm{CH}_{4}$ with $\mathrm{N}_{2}, \mathrm{CO}_{2}$ and $\mathrm{H}_{2}$ are based on the GRI-Mech 3.0 detailed chemical mechanism (Smith et al., 2000). Additional species and reactions (Qin et al., 2000) are included when $\mathrm{C}_{2} \mathrm{H}_{6}$ and $\mathrm{C}_{3} \mathrm{H}_{8}$ are added to the fuel mixture. Reactions for the formation and decay of $\mathrm{OH}^{*}$ and $\mathrm{CH}^{\star}$ are also integrated in the chemical scheme following Smith et al. (2002) and Alviso et al. (2015). The simulation gives all the flow field variables and the concentration profiles of all species including $\mathrm{OH}^{*}$ and $\mathrm{CH}^{\star}$. The procedure explained by Kojima et al. (2005) is used to take into account the fluorescence yield $y_{i}$, i.e. the fraction of radiative 
decay of the $i^{\text {th }}$ excited radical $\left(\mathrm{OH}^{*}\right.$ and $\left.\mathrm{CH}^{*}\right)$. The chemiluminescence intensity $I_{i}$ of the $i^{\text {th }}$ excited species $\left(\mathrm{OH}^{\star}\right.$ or $\left.\mathrm{CH}^{\star}\right)$ can be written as:

$$
I_{i}=y_{i} c_{i}^{*}
$$

where $c_{i}^{*}$ is the concentration $\mathrm{mol} / \mathrm{cm}^{3}$ of the $i^{\text {th }}$ excited species. The fluorescence yield $y_{i}$ is given by:

$$
y_{i}=\frac{A_{21}}{A_{21}+Q_{21}}
$$

where $A_{21}$ denotes the rate of radiative decay and $Q_{21}$ the global rate of quenching, calculated by:

$$
Q_{21}=\sum_{j} c_{j} k_{j}
$$

with $c_{j}$ the concentration of the $j^{\text {th }}$ perturbing molecule $\left(\mathrm{N}_{2}, \mathrm{O}_{2}, \mathrm{H}_{2} \mathrm{O}, \mathrm{H}_{2}, \mathrm{CO}, \mathrm{CO}_{2}, \mathrm{CH}_{4}\right)$ and $k_{j}$ the corresponding quenching reaction rate. The quantities $A_{21}$ and $k_{j}$ can be found in the chemical reaction mechanism. The quenching due to $\mathrm{C}_{2} \mathrm{H}_{6}$ and $\mathrm{C}_{3} \mathrm{H}_{8}$ is not considered due to a lack of reaction data.

The chemical mechanism used for the simulation does not include $\mathrm{CO}_{2}^{*}$ radicals. Its intensity is determined with a simplified model assuming that the radicals are created by the combination of $\mathrm{CO}$ and $\mathrm{O}\left(\mathrm{CO}+\mathrm{O} \rightarrow \mathrm{CO}_{2}^{*}\right)$, as proposed by Samaniego et al. (1995). The $\mathrm{CO}_{2}^{*}$ intensity could therefore be expressed by:

$$
I_{\mathrm{CO}_{2}^{*}}=I_{\mathrm{CO}_{2}^{*}}^{0} \cdot c_{\mathrm{CO}} \cdot c_{\mathrm{O}}
$$

where $c_{\mathrm{CO}}$ and $c_{\mathrm{O}}$ represent the concentration of $\mathrm{CO}$ and $\mathrm{O}$, respectively. The intensity $I_{\mathrm{CO}_{2}^{*}}^{0}$ depends on temperature, and is given, according to Samaniego et al. (1995), by:

$$
I_{\mathrm{CO}_{2}^{*}}^{0}=2.5 \times 10^{6} e^{-1600 / T}
$$

Where $\mathrm{T}$ is the temperature in Kelvin. The fluorescence yield $y$ is not taken into account to estimate the $\mathrm{CO}_{2}^{*}$ intensity, due to a lack of reaction data.

The resulting chemiluminescence intensity profile $I_{i}$ is integrated over the numerical domain $x=0-3 \mathrm{~mm}$ to get the total chemiluminescence intensity of a unit surface area:

$$
<I_{i}>_{\text {unit surface }}=\int_{0}^{L} I_{i} d x
$$

where $L=3 \mathrm{~mm}$ represents the limit of the flame front.

In the experiments, when secondary components are added to the fuel, the surface area of the flame front is not constant due to changes in the bulk velocity of the fuel-air mixture and flame speed of the combustible mixture. To ease the comparison with experiments, the chemiluminescence intensity per unit flame surface area given by Eq. (6) for the $i^{\text {th }}$ excited radical is divided by the thermal power per unit flame surface area to obtain the intensity per unit power: 


$$
<I_{i}>_{\text {unit power }}=\frac{\int_{0}^{L} I_{i} d x}{\rho_{0} u_{0} \sum_{k} Y_{k} \Delta h_{k}^{0}}
$$

where $\Delta h_{k}^{0}$ is the reaction enthalpy per unit mass of the $k^{\text {th }}$ combustible species $\left(\mathrm{CH}_{4}, \mathrm{H}_{2}\right.$, $\mathrm{C}_{2} \mathrm{H}_{6}, \mathrm{C}_{3} \mathrm{H}_{8}$ ). In Eq. (7), it is assumed that the flame has a perfect conical shape.

\section{Flame ionization current}

\subsection{Effects of probe position, gas velocity and fuel composition}

The ionization current measured with different probe positions, specified by the tip coordinates, is presented in Figure 4. It is found that when the probe is in contact with, or very close to the flame front, the current intensity is roughly unaltered by the probe positions. In this case, the conical flame shape is deformed by the probe, but this perturbation does not change the current intensity. When the probe tip is located in the lower left part of the graph, the probe, inserted from the right, crosses in this case entirely the flame. A larger area of contact between the flame and the probe, serving as anode, leads to a slight increase of the current intensity as already observed by Franke (2002). On the other hand, when the tip is located in the right of the graph, the probe is only in contact with the burnt gases and the ionization current decreases and finally drops to zero when the probe is completely outside the zone of burnt gases.

Figure $5 \mathrm{a}$ shows the evolution of the ionization current with the gas velocity (flame power), for different probe positions. These data show different trends with respect to the gas velocity. This is due to the simultaneous impact of two factors i.e. the gas velocity and

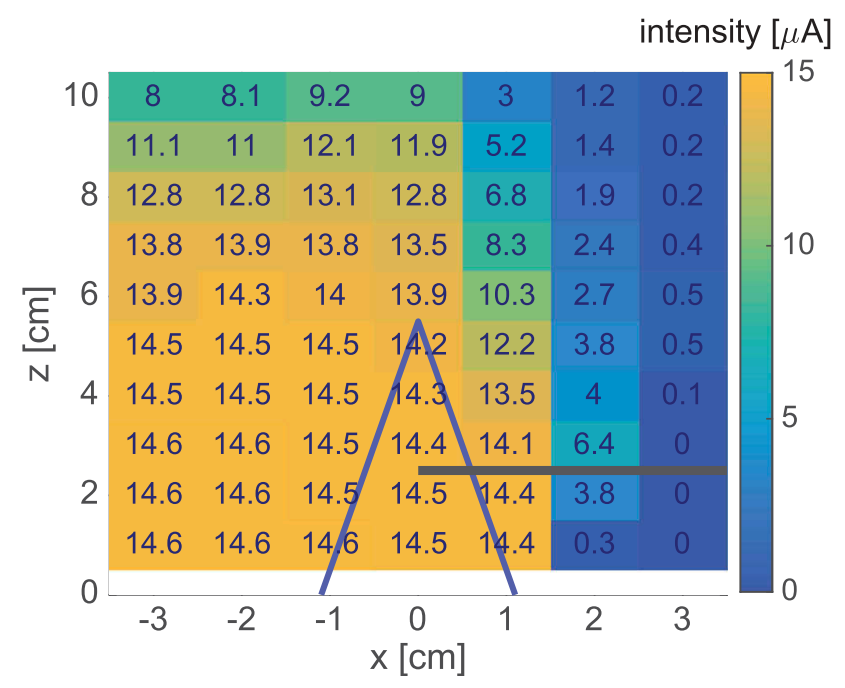

Figure 4. Ionization current at specific probe positions specified by its tip coordinates. (methane - air flame, $u=1.5 \mathrm{~m} / \mathrm{s}, \Phi=0.83, U_{\text {bias }}=300 \mathrm{~V}$ ). The conical flame front is delineated by the blue strip and the (moving) ionization probe inserted from the right by the black strip. The color map gives the current intensity. 


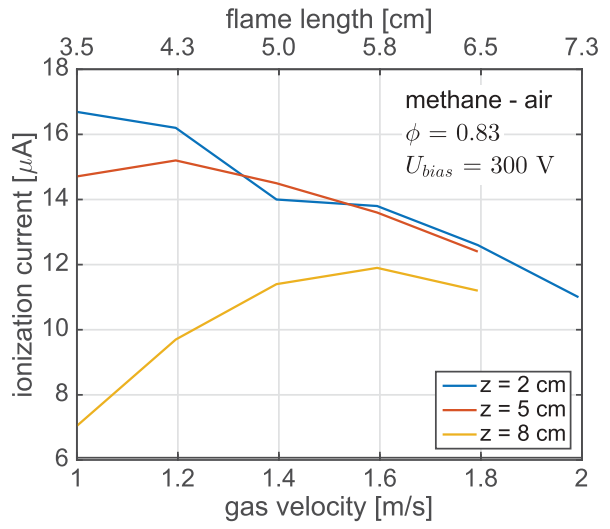

(a)

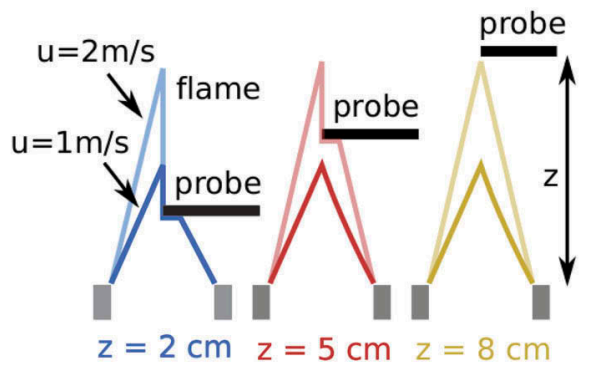

(b)

Figure 5. Evolution of the ionization current with the gas velocity. In the left plot, the flow velocities are given at the bottom. The corresponding flame lengths are at the top. These values are only valid when the flame lies below the altitude $z$ at which the probe is set. Otherwise the flame is deformed by the ionization probe. (a) lonization current vs. gas velocity" and "(b) Indicative flame topology with different gas velocities and probe positions.

the probe-flame distance. This phenomenon is schematically illustrated in Figure 5b. At $z=2 \mathrm{~cm}$, the probe is in contact with the flame over the whole range of gas velocities explored. The ionization current decreases monotonically for increasing gas flow velocities. At $z=5 \mathrm{~cm}$, the current increases at low gas velocities due to a reduced distance between the flame and the probe. Once the flame reaches the probe for a flow velocity $u=1.4 \mathrm{~m} / \mathrm{s}$, the probe position is no longer important and the red curve $(z=5 \mathrm{~cm})$ joins the blue one $(z=2 \mathrm{~cm})$. A similar trend is seen for $z=8 \mathrm{~cm}$ but the maximum current is achieved at a higher gas velocity. The same type of evolution, with a maximum current at intermediate power, has been observed in real gas boilers as well by Kiefer et al. (2012).

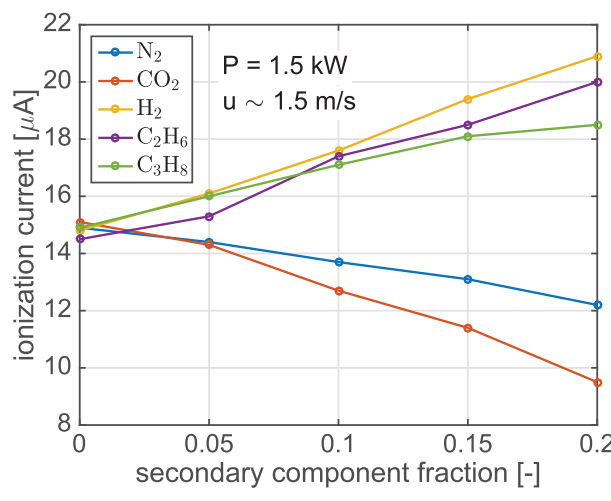

(a)

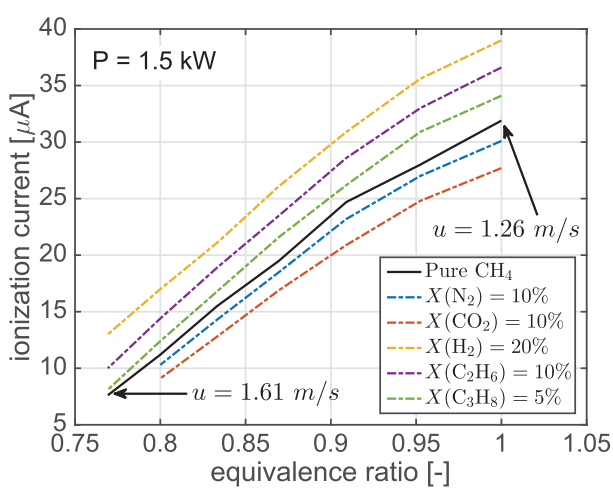

(b)

Figure 6. Effects of secondary natural gas components on the ionization current. (a) lonization current vs. secondary component molar fraction $(\$ P \$=1.5 \mathrm{~kW}, \$ \mathrm{phi} \$=0.83)^{\prime \prime}$ and (b) lonization current vs. equivalence ratio with different fuel scenarios $(\$ P \$=1.5 \mathrm{~kW})$. 
The impact of secondary components, $\mathrm{N}_{2}, \mathrm{CO}_{2}, \mathrm{H}_{2}, \mathrm{C}_{2} \mathrm{H}_{6}, \mathrm{C}_{3} \mathrm{H}_{8}$ in the fuel mixture is now investigated. The flame power is fixed at $P=1.5 \mathrm{~kW}$ and the ionization probe is set at a height of $z=2 \mathrm{~cm}$ above the burner outlet. In these conditions, the probe is always in contact with the flame reaction layer. In these experiments, the secondary components are progressively added to methane from $X=0$ to $20 \%$ where $X$ represents the volumetric fraction of the secondary component with respect to the methane and secondary component blend, while the equivalence ratio is kept constant at $\phi=0.83$. It is found that the injection of $\mathrm{N}_{2}$ and $\mathrm{CO}$ causes a decrease while $\mathrm{H}_{2}, \mathrm{C}_{3} \mathrm{H}_{8}$, and $\mathrm{C}_{2} \mathrm{H}_{6}$ additions cause an increase of the ionization current, as shown in Figure 6a. The gas velocity at the burner outlet varies by less than $3 \%$ for the different fuel mixtures hence its impact on the ionization current intensity is negligible.

The response of the ionization current as a function of the equivalence ratio is now investigated with binary fuel blends. The volumetric fractions of secondary components are as follows: $X\left(\mathrm{~N}_{2}\right)=10 \%, X\left(\mathrm{CO}_{2}\right)=10 \%, X\left(\mathrm{H}_{2}\right)=20 \%, \quad X\left(\mathrm{C}_{2} \mathrm{H}_{6}\right)=10 \%$, $X\left(\mathrm{C}_{3} \mathrm{H}_{8}\right)=5 \%$. They are chosen to represent the maximum value expected in future natural gas blends by also considering the injection of biogas and hydrogen. The flame power remains constant at $P=1.5 \mathrm{~kW}$ and the probe is fixed at $z=2 \mathrm{~cm}$. Results for the ionization current intensity are plotted as a function of equivalence ratio, as shown in Figure $6 \mathrm{~b}$. It is found that all the secondary components cause a drift from the pure methane curve but the gaps remain relatively small. The errors made in sensing the equivalence ratio remain moderate. The maximum difference is observed for $20 \%$ vol. $\mathrm{H}_{2}$ addition, with a shift of $\Delta \phi=0.08$ for the same flame ionization current and a system operated with pure methane at the same equivalence ratio $\phi$. The error is the largest when approaching stoichiometric conditions. In all other cases, differences between the current with and without secondary component are lower leading to differences in equivalence ratio lower than $\Delta \phi=0.05$ for $0.80 \leq \phi \leq 1.00$.

It is worth recalling that the ionization current depends on the gas velocity and the curves shown in Figure 6 are only valid for the given power $P=1.5 \mathrm{~kW}$. As the power remains fixed in these experiments, the gas velocity $u$ also changes with the equivalence ratio. For the pure methane/air mixture, the bulk flow velocity changes from $u=1.61 \mathrm{~m} / \mathrm{s}$ at $\phi=0.77$ to $u=1.26 \mathrm{~m} / \mathrm{s}$ at $\phi=1.00$ as indicated in Figure $6 \mathrm{~b}$. When the flame remains in contact with the probe tip, it has been shown in Figure 5 that the ionization current slightly drops as the velocity increases. Nevertheless, the change of the ionization current by a factor of 4 from $\phi=0.77$ to $\phi=1.00$, shown in Figure 6b, is mainly due to the equivalence ratio.

\subsection{Ionization current vs. dead space size}

An attempt is made to interpret the changes for the ionization current with the gas velocity, equivalence ratio and fuel composition. The approach builds on the work from Rodrigues (2005) and Karrer et al. (2010). In the experiments conducted by Rodrigues (2005) with two electrodes inserted into a planar flame it is concluded that the drop of electrical potential takes place essentially near the cathode. Using a 1-D flame model, both Rodrigues (2005) and Karrer et al. (2010) demonstrate that the ionization current intensity is related to the quenching distance near the cathode. 


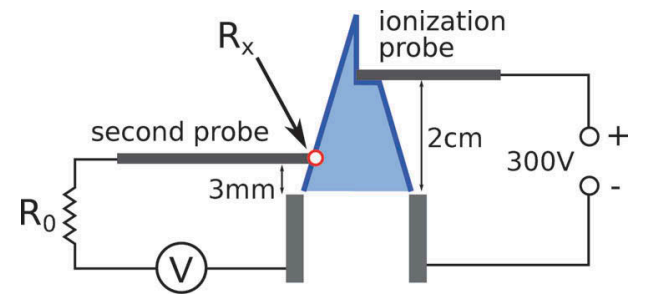

(a) Configuration

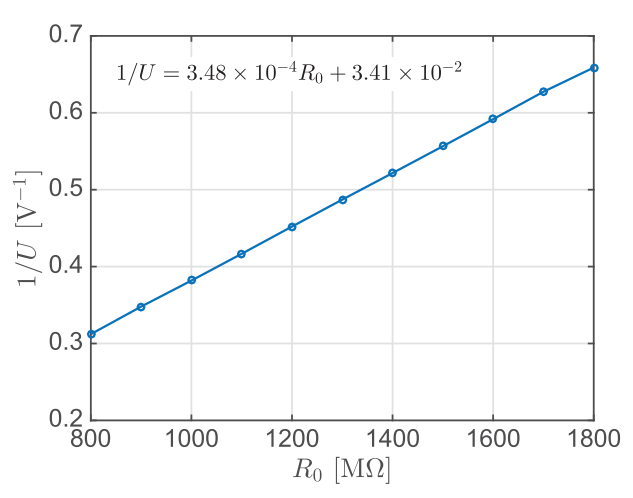

(b) $1 / U$ vs. $R_{0}$

Figure 7. Flame front electrical potential measurement.

It is worth examining whether these findings are applicable to this conical flame configuration investigated in this study. In the following experiments, the electrical potential of the flame front is determined using the ionization probe and the metallic burner respectively as anode and cathode. The dead space size corresponding to the standoff distance between the flame base and the burner rim is also measured.

The flame front potential can be measured with a second probe as shown in Figure 7, set at a height of about $3 \mathrm{~mm}$ above the burner. However, the inert space between the flame and probe also constitutes a huge resistance of the order of $100 \mathrm{M} \Omega$, much higher than the input impedance of usual voltmeters of the order of $10 \mathrm{M} \Omega$ and the voltage cannot directly be read from the voltmeter. To overcome this difficulty, an additional resistor $R_{0}$ is added in series with the voltmeter. The resistance $R_{0}$ is varied and the voltmeter readout $U$ is recorded. These quantities are linked by:

$$
\frac{1}{U}=\frac{1}{R_{v} U_{f}} R_{0}+\frac{R_{v}+R_{x}}{R_{v} U_{f}}
$$

where $R_{v}$ is the voltmeter impedance, $R_{x}$ the unknown resistance between the flame and probe. The voltage $U_{f}$ between the flame and the burner rim is deduced from the regression of the data gathered at different resistances $R_{0}$. Measurements are made with a methane-air flame of $1.5 \mathrm{~kW}$ and equivalence ratio $\phi=0.83$. The voltage generator is set at $300 \mathrm{~V}( \pm 0.1 \%)$. The resistance $R_{0}$ is varied between $800 \mathrm{M} \Omega$ and $1.8 \mathrm{G} \Omega$. The high resistances make sure that the measurement branch do not perturb the initial electrical circuit, and that the variations of $R_{x}$ are negligible. The voltmeter impedance $R_{v}$ is about 10.1 $\mathrm{M} \Omega$ in the corresponding range $(1 \mathrm{mV}-4 \mathrm{~V})$. The relative uncertainties for $R_{0}$ and $R_{v}$ are below $1 \%$. The response $1 / U$ as a function of $R_{0}$ in Figure $7 \mathrm{~b}$ shows a very good linearity, and the linear regression gives $R_{x} \sim 90 \mathrm{M} \Omega$ and $U_{f}=284 \mathrm{~V}$, which has to be compared to the voltage source $300 \mathrm{~V}$. These experiments confirm that the major electrical potential drop takes place near the cathode. These results suggest that the ionization current is mainly determined by the flow and flame properties near the cathode. This also explains why the ionization current shown in Figure 4 is relatively insensitive to the probe 
Table 1. Test conditions for dead space size measurement.

\begin{tabular}{lcccc}
\hline No. & Power $[\mathrm{kW}]$ & Equivalence ratio & Fuel & Secondary gas vol.\% \\
\hline 1 & 1.5 & $1.00,0.91,0.83,0.77$ & $\mathrm{CH}_{4}$ & \\
2 & $1.0,1.4,1.8$ & 0.83 & $\mathrm{CH}_{4}$ & \\
3 & 1.5 & 0.83 & $\mathrm{CH}_{4} / \mathrm{CO}_{2}$ & $X\left(\mathrm{CO}_{2}\right)=0,10 \%, 20 \%$ \\
4 & 1.5 & 0.83 & $\mathrm{CH}_{4} / \mathrm{H}_{2}$ & $X\left(\mathrm{H}_{2}\right)=0,10 \%, 20 \%$ \\
5 & 1.5 & 0.83 & $\mathrm{CH}_{4} / \mathrm{C}_{3} \mathrm{H}_{8}$ & $X\left(\mathrm{C}_{3} \mathrm{H}_{8}\right)=0,10 \%, 20 \%$ \\
\hline
\end{tabular}

position, constituting the anode in the electrical circuit, as long as it is in contact with the flame front.

Conical flames are stabilized at a finite distance from the burner rim because the combustion reaction is quenched close to solid walls. This dead space may explain for the huge electrical resistance near the cathode and its size can be related to the ionization current. The flame base is stabilized at the point where an equilibrium is achieved between the local burning velocity and the local bulk gas velocity (Lewis and Von Elbe, 1987). When the adiabatic laminar burning velocity is reduced or when the gas velocity is increased, in order to maintain the equilibrium, the stabilization point has to shift downstream and enhance the burning velocity by reducing the heat loss. It leads then to a larger flame stand-off distance (Altendorfner et al., 2011; Cullen, 1950; Kedia, 2010).

In the present study, the flame standoff distance is measured with an intensified CCD camera, for different powers (gas flowrates), equivalence ratios, and fuel compositions, as listed in Table 1. This distance increases with $\mathrm{CO}_{2}$ dilution, a higher gas velocity or a lower equivalence ratio. It is reduced by the enrichment with $\mathrm{H}_{2}$, while the enrichment with $\mathrm{C}_{3} \mathrm{H}_{8}$ does not cause any clear changes. All these results are in agreement with the above analysis on the effects of gas velocity and adiabatic laminar burning velocity.

The ionization current is then plotted as a function of the dead space size, as shown in Figure 8. A low ionization current is almost always related to a large dead space. These two quantities are well correlated when the power, equivalence ratio $(\phi \leq 0.83$ or

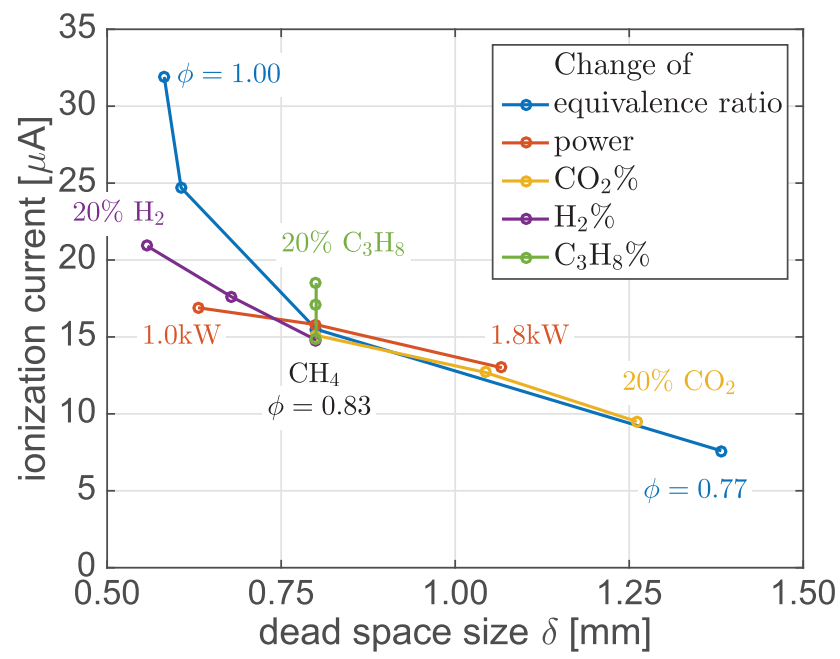

Figure 8. Ionization current vs. dead space size. 
$\delta>1.5 \mathrm{~mm}$ ), the $\mathrm{H}_{2}$ or $\mathrm{CO}_{2}$ molar fraction in the mixture blend are varied, meaning that the effect of dead space size is dominant.

Deviations are observed when the equivalence ratio gets closer to stoichiometry. Also, the $\mathrm{C}_{3} \mathrm{H}_{8}$ injection barely modifies the dead space size while the ionization current increases. These deviations may result from factors that were neglected in this study, such as the populations of ions and the detailed electrical field near the cathode. Nevertheless, this correlation between the ionization current intensity and the size of dead space allows to interpret the main features of the evolution of the ionization current with the different flame parameters tested. It also qualitatively provides an experimental support for the theoretical analyses from Rodrigues (2005) and Karrer et al. (2010).

\section{Flame chemiluminescence}

\subsection{Effects of fuel composition}

The impact of secondary natural gas components on the flame chemiluminescence is investigated with similar methods as in Section 3.1. The experiments are first performed at a fixed power $\left(P=1.3 \mathrm{~kW}\right.$ for $\mathrm{N}_{2}$ and $\mathrm{CO}_{2}$ dilution, and $P=1.5 \mathrm{~kW}$ for $\mathrm{H}_{2}, \mathrm{C}_{2} \mathrm{H}_{6}, \mathrm{C}_{3} \mathrm{H}_{8}$ enrichment) and a fixed equivalence ratio $(\phi=0.83)$, while the volumetric fraction of secondary components varies from $X=0 \%$ to $20 \%$. When the secondary component is a combustible $\left(\mathrm{H}_{2}, \mathrm{C}_{2} \mathrm{H}_{6}, \mathrm{C}_{3} \mathrm{H}_{8}\right)$, the power and equivalence ratio values refer to the air/ methane/secondary component mixture.

The chemiluminescence intensities of $\mathrm{OH}^{*}, \mathrm{CH}^{*}$, and $\mathrm{CO}_{2}^{*}$ are normalized by their values for the pure methane case, and drawn against the volumetric fraction $X$, as shown in Figure 9 (circles with error bars). The numerical results calculated with Eq. (7) are presented as dashed lines in the same figure. It is shown that:

- The injection of $\mathrm{N}_{2}$ only slightly reduces the $\mathrm{CH}^{*}, \mathrm{OH}^{*}$, and $\mathrm{CO}_{2}^{*}$ emissions $(<5 \%$ for $X\left(\mathrm{~N}_{2}\right)=20 \%$ )

- The injection of $\mathrm{CO}_{2}$ causes a small decrease of $\mathrm{CH}^{\star}, \mathrm{OH}^{*}$ (around $10 \%$ for $\left.X\left(\mathrm{CO}_{2}\right)=20 \%\right)$, and a slight increase of $\mathrm{CO}_{2}^{*}\left(<5 \%\right.$ for $\left.X\left(\mathrm{CO}_{2}\right)=20 \%\right)$

- $\mathrm{H}_{2}$ barely changes the emission of $\mathrm{OH}^{*}$, but causes a clear decrease of $\mathrm{CH}^{\star}(>15 \%$ for $\left.X\left(\mathrm{~N}_{2}\right)=20 \%\right)$ and a small decrease of $\mathrm{CO}_{2}^{*}\left(<10 \%\right.$ for $\left.X\left(\mathrm{H}_{2}\right)=20 \%\right)$

- Addition of $\mathrm{C}_{2} \mathrm{H}_{6}$ or $\mathrm{C}_{3} \mathrm{H}_{8}$ causes a clear increase of $\mathrm{OH}^{*}$ and $\mathrm{CO}_{2}^{*}(>10 \%$ for $X=20 \%)$, and a remarkable increase of $\mathrm{CH}^{*}(>150 \%$ for $X=20 \%)$. For the same volumetric fraction, $\mathrm{C}_{3} \mathrm{H}_{8}$ injection has a stronger impact on the chemiluminescence intensities than $\mathrm{C}_{2} \mathrm{H}_{6}$.

The most remarkable is the effect of $\mathrm{C}_{2} \mathrm{H}_{6}$ or $\mathrm{C}_{3} \mathrm{H}_{8}$ addition on the $\mathrm{CH}^{\star}$ intensity as even a small fraction causes a significant increase. One explanation is that the longer chains of carbon of these fuels facilitate the formation of $\mathrm{C}_{2} \mathrm{H}$ species, a predecessor of the $\mathrm{CH}^{*}$ radical.

The numerical results reproduce the changes caused by $\mathrm{N}_{2}, \mathrm{CO}$ dilution and $\mathrm{H}_{2}$ enrichment with satisfaction (Figure 9, left column). Only the $\mathrm{CH}^{*}$ intensity with $\mathrm{H}_{2}$ injection shows relatively big differences with respect to the experiments. This might be caused by the shape of the conical flames obtained with hydrogen enriched mixtures. With 

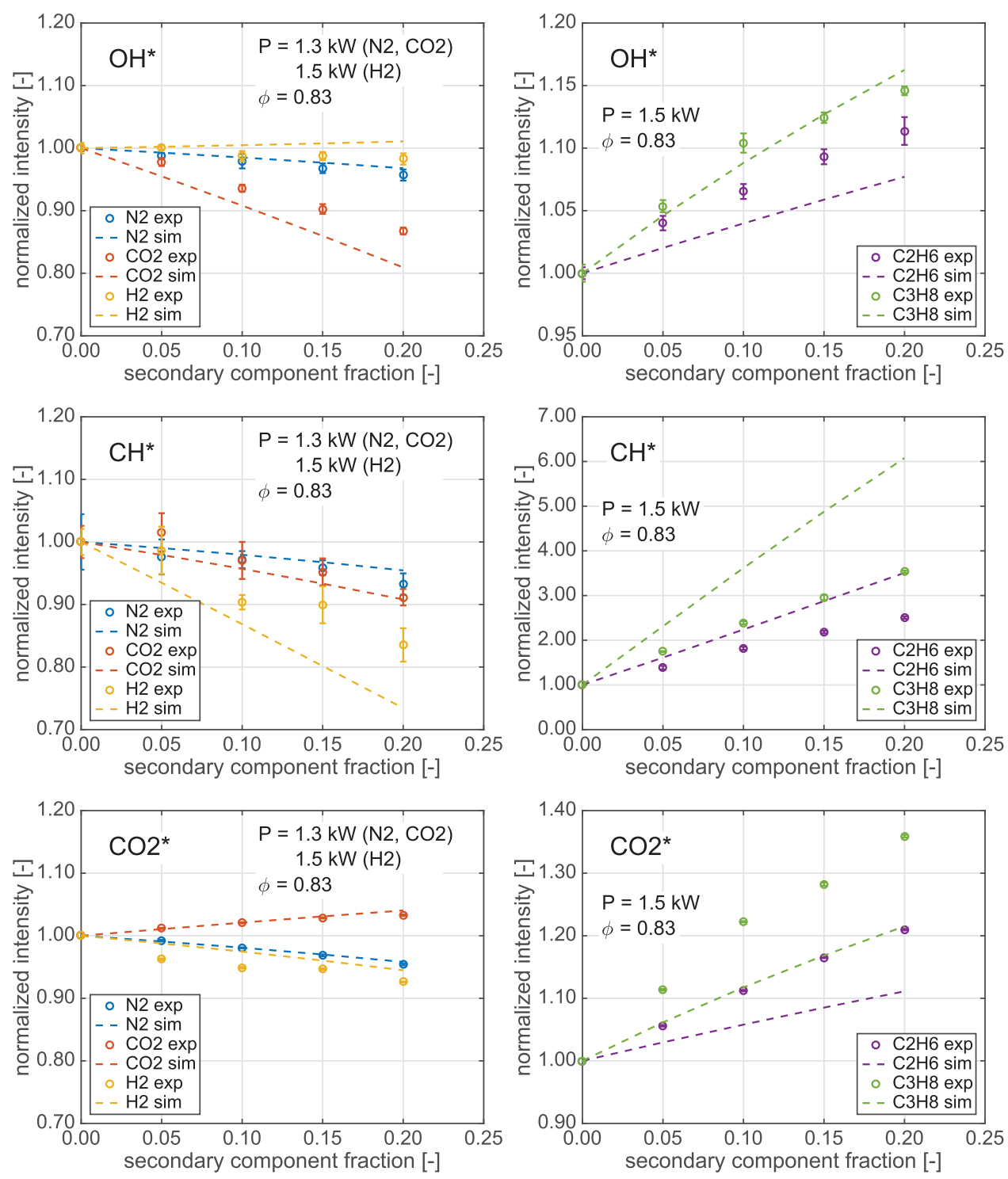

Figure 9. Evolution of chemiluminescence intensity with secondary component volumetric fraction.

$20 \%$ vol. $\mathrm{H}_{2}$ injection, a clear thermo-diffusive instability is observed in the experiments. The flame shape is altered by periodic cells with changes of the flame luminosity along the flame front. However, larger differences between numerical and experimental results are observed for $\mathrm{C}_{2} \mathrm{H}_{6}$ and $\mathrm{C}_{3} \mathrm{H}_{8}$ enriched flames (Figure 9, right column), probably because the reaction mechanism is not suited for these fuel blends.

The $\mathrm{CH}^{\star} / \mathrm{OH}^{*}$ intensity ratio is now investigated as a function of equivalence ratio for pure methane and five binary mixtures consisting of methane and one secondary component. Experiments are made only at a unique flame power due to stabilization issues, but the ratio of two chemiluminescence intensities removes a priori the impact of flame power (Higgins et al., 2001a, 2001b; Hurle et al., 1968). The resulting curves are shown in 


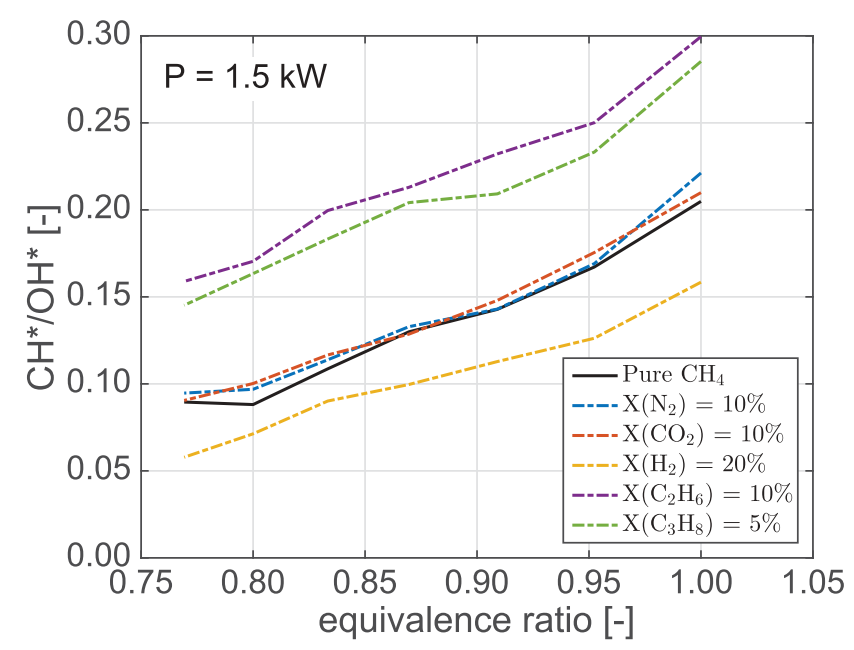

Figure 10. $\mathrm{CH}^{*} / \mathrm{OH}^{*}$ vs. equivalence ratio for different fuel blend compositions.

Figure 10. It is found that the calibration curve obtained with pure methane (black solid line) remains valid for combustible mixtures slightly diluted by $\mathrm{N}_{2}$ or $\mathrm{CO}_{2}$. Addition of $\mathrm{H}_{2}$ yields a noticeable error of the predicted equivalence ratio $\left(\Delta \phi \sim 0.05\right.$ for $\left.X\left(\mathrm{H}_{2}\right)=20 \%\right)$. For $\mathrm{C}_{2} \mathrm{H}_{6}$ and $\mathrm{C}_{3} \mathrm{H}_{8}$ addition, even a modest fraction of a few per cents in the fuel mixture causes considerable errors $(\Delta \phi>0.1)$, which may not be acceptable for combustion control. The gaps for the results of $\mathrm{H}_{2}, \mathrm{C}_{2} \mathrm{H}_{6}$ and $\mathrm{C}_{3} \mathrm{H}_{8}$ enrichment with respect to pure $\mathrm{CH}_{4}$ result clearly from the different effects of these components on $\mathrm{CH}^{*}$ and $\mathrm{OH}^{*}$ revealed in Figure 9.

\subsection{Chemiluminescence intensity vs. burnt gas temperature}

Changes of the flame chemiluminescence intensity with the injection of secondary natural gas components may result from several factors, but it is natural to first investigate if this could be related to changes of the flame temperature. It has been shown in the previous section that the numerical methodology allows to well reproduce the $\mathrm{OH}^{*}, \mathrm{CH}^{*}$ and $\mathrm{CO}_{2}^{*}$ emission intensities observed in the experiments from $\mathrm{N}_{2}$-diluted, $\mathrm{CO}_{2}$-diluted, and $\mathrm{H}_{2}$ enriched methane/air mixtures. It is used here to examine whether these changes could be exclusively attributed to the modifications of the flame temperature.

The flame conditions for this investigation are listed in Table 2, with a set of combustible mixtures featuring different inlet gas temperature $T_{0}$, equivalence ratio and $\mathrm{N}_{2}, \mathrm{CO}_{2}$,

Table 2. Operating conditions for the analysis of the chemiluminescence intensity as a function of the burnt gas temperature.

\begin{tabular}{lccc}
\hline Fuel & $T_{0}(\mathrm{~K})$ & $\phi$ & Secondary gas vol.\% \\
\hline $\mathrm{CH}_{4}$ & $160-460$ & 0.83 & \\
$\mathrm{CH}_{4}$ & 298 & $0.75-0.92$ & \\
$\mathrm{CH}_{4} / \mathrm{N}_{2}$ & 298 & 0.83 & $X\left(\mathrm{~N}_{2}\right)=0-0.30$ \\
$\mathrm{CH}_{4} / \mathrm{CO}_{2}$ & 298 & 0.83 & $X\left(\mathrm{CO}_{2}\right)=0-0.30$ \\
$\mathrm{CH}_{4} / \mathrm{H}_{2}$ & 298 & 0.83 & $X\left(\mathrm{H}_{2}\right)=0-0.30$ \\
\hline
\end{tabular}




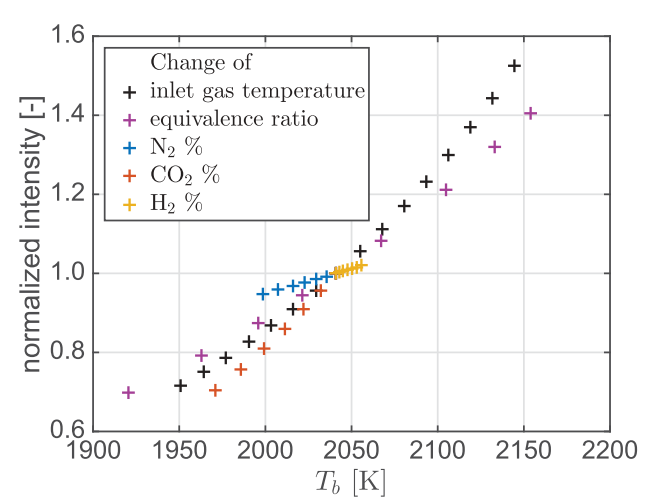

(a) $\mathrm{OH}^{*}$

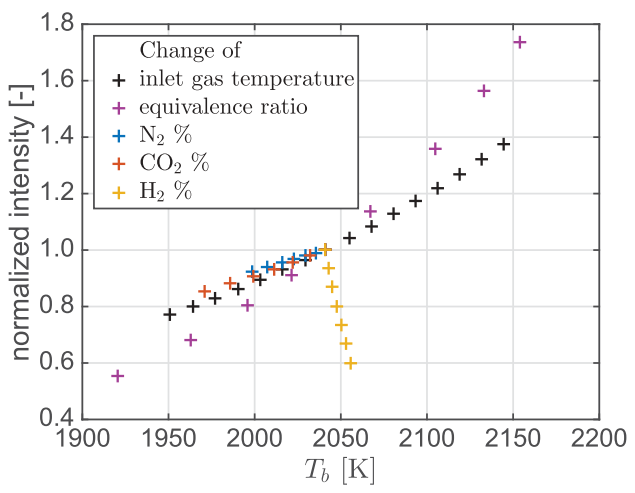

(b) $\mathrm{CH}^{*}$

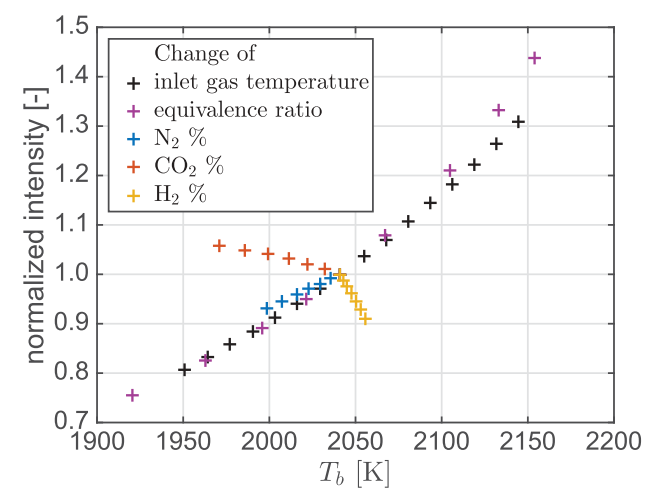

(c) $\mathrm{CO}_{2}^{*}$

Figure 11. Numerical results for the chemiluminescence intensity per unit power as a function of the burnt gas temperature $T_{b}$ for different inlet gas temperature $T_{0}$, equivalence ratio $\Phi$ and secondary component molar fraction $X^{\text {fuel }}$ listed in Table 2 . Intensity values are normalized according to a methane-air flame at $\Phi=0.83$ and $T_{0}=298 \mathrm{~K}$.

and $\mathrm{H}_{2}$ injection. Injections of $\mathrm{C}_{2} \mathrm{H}_{6}$ and $\mathrm{C}_{3} \mathrm{H}_{8}$ is not considered in this analysis. One may however already conclude that in these cases the flame temperature is not major factor altering the chemiluminescence intensity, as shown in the right column in Figure 9, because the flame temperature barely changes with $\mathrm{C}_{2} \mathrm{H}_{6}^{*}$ and $\mathrm{C}_{3} \mathrm{H}_{8}^{*}$ enrichment at fixed equivalence ratio.

The chemiluminescence intensity per unit power calculated with Eq. (7) is drawn in Figure 11 as a function of the burnt gas temperature $T_{b}$. The analysis carried out in this section is similar to the work of Samaniego et al. (1995) but with two differences. First, the emission intensities as shown in Figure 11 are given per unit power, while Samaniego et al. (1995) presented their results per unit surface area. Second, Samaniego et al. (1995) limited their results to the $\mathrm{CO}_{2}^{*}$ emission at two equivalence ratios and for $\mathrm{N}_{2}$ diluted methane/air flames, while in the present work, it is extended to include $\mathrm{CO}_{2}$ dilution and $\mathrm{H}_{2}$ enrichment, and three radicals $\mathrm{OH}^{\star}, \mathrm{CH}^{\star}$ and $\mathrm{CO}_{2}^{*}$.

As shown in Figure 11a, results for the $\mathrm{OH}^{\star}$ intensity increase with the burnt gas temperature, yet the slopes for each data series are different. Therefore the flame 
temperature alone is not sufficient to account for the changes of $\mathrm{OH}^{*}$ intensity. For the $\mathrm{CH}^{\star}$ signal, as shown in Figure $11 \mathrm{~b}, \mathrm{~N}_{2}$ and $\mathrm{CO}_{2}$ dilution of methane-air mixtures have the same effect as a change of inlet gas temperature $T_{0}$. The corresponding markers collapse almost on the same curve. A slight deviation from this curve is observed when the equivalence ratio of the methane-air mixture is varied (magenta markers). One possible explanation is that the higher $\mathrm{CH}_{4}^{*}$ molar fraction in richer flames promotes the formation of the $\mathrm{C}_{2} \mathrm{H}$ species, predecessor of $\mathrm{CH}^{*}$, thanks to more frequent $\mathrm{C} 1-\mathrm{C} 1$ (species with one carbon atom) molecule collisions. Another difference shown in Figure $11 \mathrm{~b}$ concerns the results obtained with $\mathrm{H}_{2}$ enrichment, showing a completely different trend as the other cases studied. It is reminded that with $30 \%$ vol. $\mathrm{H}_{2}$ injection in the fuel blend, the $\mathrm{CH}_{4}^{*}$ flow rate is reduced by about $11 \%$ in order to keep the power constant, which contributes partly to the drop of $\mathrm{CH}$ intensity. Also, $\mathrm{H}_{2}$ enrichment hinders the formation of $\mathrm{CH}^{*}$. As shown in Figure 11c, the modification of the $\mathrm{CO}_{2}^{*}$ intensity with the equivalence ratio and the $\mathrm{N}_{2}$ dilution lead to the same response as a change of inlet gas temperature of a methane-air mixture. The deviations observed for $\mathrm{CO}_{2}$ dilution and $\mathrm{H}_{2}$ enrichment can be attributed respectively to a higher and lower number of carbon atoms in the reactive mixture. The decrease of $\mathrm{CO}_{2}^{*}$ intensity with $\mathrm{H}_{2}$ enrichment roughly corresponds to the decrease of $\mathrm{CH}_{4}$ flow rate.

Table 3. Estimated errors $(\Delta \Phi)$ of predicted equivalence ratio within $0.77 \leq \Phi \leq 1.00$.

\begin{tabular}{lccc}
\hline Fuel scenario & Ionization current & Chemiluminescence & Coupled \\
\hline $\mathrm{CH}_{4}$ with $X\left(\mathrm{~N}_{2}\right)=10 \%$ & $0.01-0.02(-)$ & $0.01-0.02(+)$ & $\sim 0.01$ \\
$\mathrm{CH}_{4}$ with $X\left(\mathrm{CO}_{2}\right)=10 \%$ & $0.02-0.05(-)$ & $0.01-0.02(+)$ & $<0.02$ \\
$\mathrm{CH}_{4}$ with $X\left(\mathrm{H}_{2}\right)=20 \%$ & $0.05-0.08(+)$ & $\sim 0.05(-)$ & $\sim 0.01$ \\
$\mathrm{CH}_{4}$ with $X\left(\mathrm{C}_{2} \mathrm{H}_{6}\right)=10 \%$ & $0.02-0.05(+)$ & $0.1-0.15(+)$ & $\sim 0.05(+)$ \\
$\mathrm{CH}_{4}$ with $X\left(\mathrm{C}_{3} \mathrm{H}_{8}\right)=5 \%$ & $0.01-0.03(+)$ & $0.1-0.15(+)$ & $0.05-0.1(+)$ \\
\hline
\end{tabular}

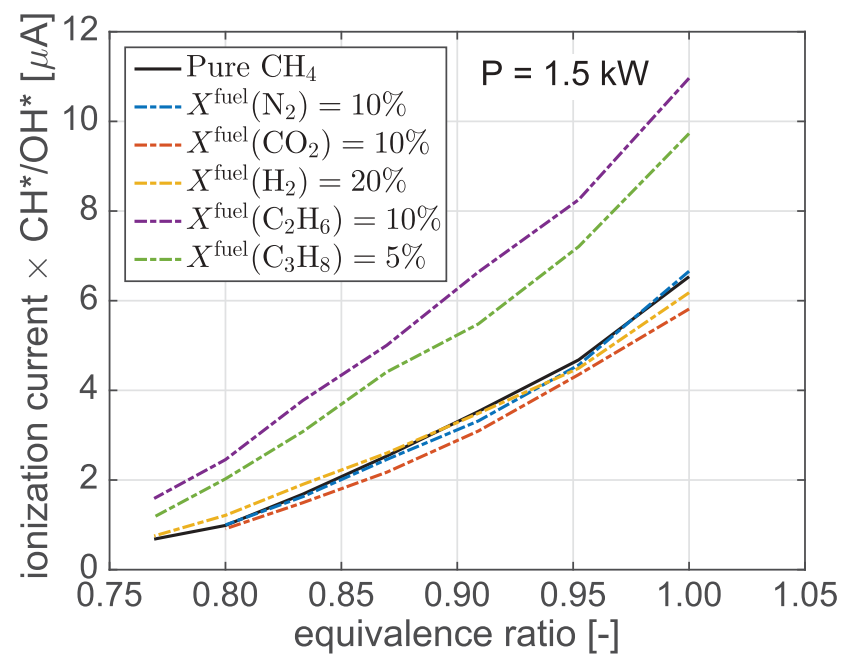

Figure 12. Ionization current $\times \mathrm{CH}^{*} / \mathrm{OH}^{*}$ vs. equivalence ratio under different fuel composition scenarios. 


\section{Coupled sensing with both techniques}

The impact of the natural gas composition on the equivalence ratio sensing by examining the flame ionization current or the chemiluminescence signal has been described in Section 3.1 and 4. Based on Figures $6 \mathrm{~b}$ and 10, estimated bias errors of the predicted equivalence ratio with the two techniques are summarized in Table 3 for five gas composition scenarios. The + and - signs in the parentheses respectively mean that the predicted equivalence ratio is higher and lower than the real value. It is recalled that the magnitude of the error made depends on the secondary component fraction in the fuel blend.

Since the flame ionization current and chemiluminescence signal are two independent processes, a sensing strategy can be conceived coupling both of them. The product of the ionization current and $\mathrm{CH}^{*} / \mathrm{OH}^{*}$ chemiluminescence intensity ratio is used in Figure 12 as an equivalence ratio indicator. The curves for $\mathrm{N}_{2}, \mathrm{CO}_{2}$, and $\mathrm{H}_{2}$ addition to methane all lie very close to the reference curve obtained for pure methane. Results for $\mathrm{C}_{2} \mathrm{H}_{6}$ and $\mathrm{C}_{3} \mathrm{H}_{8}$ still show relatively large gaps with respect to the reference case for pure methane. The errors based on the coupled sensing strategy are listed as well in Table 3. This new technique is especially advantageous in the case of $\mathrm{H}_{2}$ injection, because the ionization current and chemiluminescence signals cause bias errors in different directions, and they are neutralized by taking the product of the two signals. Nevertheless, the coupled strategy does not exclude the impact of the gas velocity on the ionization current and these curves need to be constructed for each level of power. This latter combined technique is however appealing for monitoring the equivalence ratio.

Table 3 indicates that each of the three proposed sensing strategies offers certain benefits under specific conditions. The choice therefore depends on the natural gas composition, as well as the error permitted.

- When the natural gas contains low $\mathrm{C}_{2} \mathrm{H}_{6}, \mathrm{C}_{3} \mathrm{H}_{8}$, or other heavier hydrocarbon fuels, the chemiluminescence intensity ratio $\mathrm{CH}^{*} / \mathrm{OH}^{*}$ is useful to infer the equivalence ratio and offers the advantage of being independent of the power. This equivalence ratio indicator is well suited for the unpurified biogas, consisting mainly of $\mathrm{CH}_{4}$ and $\mathrm{CO}_{2}$. However, the precision can be compromised by the injection of $\mathrm{H}_{2}$.

- When the $\mathrm{C}_{2} \mathrm{H}_{6}$ and $\mathrm{C}_{3} \mathrm{H}_{8}$ fractions are sizable in the natural gas, the ionization current method is preferred to determine the equivalence ratio, because it causes relatively small errors for all secondary components investigated.

- When $\mathrm{H}_{2}$ is injected in the natural gas and a high precision is required, the coupled sensing strategy, where the ionization current is multiplied by the $\mathrm{CH}^{*} / \mathrm{OH}^{*}$ intensity ratio, may be an appropriate choice to determine the equivalence ratio. It is robust with $\mathrm{N}_{2}, \mathrm{CO}_{2}, \mathrm{H}_{2}$ injection. Nevertheless, sizable $\mathrm{C}_{2} \mathrm{H}_{6}$ and $\mathrm{C}_{3} \mathrm{H}_{8}$ fractions in the combustible blend would cause non-negligible errors.

\section{Conclusion}

Two potential low cost techniques, flame ionization current and flame chemiluminescence, have been studied to monitor the combustion state of domestic boilers powered 
by natural gas with varying gas composition. The evolution of the ionization current with the probe position in the reacting flow, the bulk gas velocity, fuel composition and equivalence ratio has been investigated experimentally. It has been found that the modifications observed for the ionization current are related to the size of the dead space between flame base and burner rim. The analysis conducted on the chemiluminescence from $\mathrm{OH}^{*}, \mathrm{CH}^{*}$, and $\mathrm{CO}_{2}^{*}$ has been focused on effects of fuel composition and numerical simulations with a 1-D premixed flame models have been conducted as a support to the measurements.

It has been found that both the flame ionization current and chemiluminescence signal are sensitive to the equivalence ratio, which makes them candidates to monitor the combustion state of premixed systems powered by natural gas. However, these diagnostics are also disturbed by other factors. The ionization current is found to depend on the flame power (or gas velocity) and the evolution can be non-monotonic. As a result, the response of the ionization current as a function of equivalence ratio needs to be known for each level of power. The fuel composition may compromise the precision of equivalence ratio prediction, but the errors are acceptable for modest secondary gas fractions in the fuel blend.

An alternative is to use the $\mathrm{CH}^{\star} / \mathrm{OH}^{\star}$ to indicate the equivalence ratio, which is supposed to remove the impact of flame power. This indicator also gives satisfactory results when $\mathrm{N}_{2}, \mathrm{CO}_{2}$, and $\mathrm{H}_{2}$ are injected into $\mathrm{CH}_{4}$. However, when the fuel contains $\mathrm{C}_{2} \mathrm{H}_{6}$ or $\mathrm{C}_{3} \mathrm{H}_{8}$, the error rapidly increases and the $\mathrm{CH}^{\star} / \mathrm{OH}^{\star}$ intensity ratio is in these cases not a reliable indicator for the equivalence ratio. Finally, a third strategy is proposed, using the product of the ionization current and the $\mathrm{CH}^{\star} / \mathrm{OH}^{\star}$ intensity ratio to determine the equivalence ratio. This coupled sensing strategy for the equivalence ratio especially improves the combustion state monitoring in case of $\mathrm{H}_{2}$ injection in the natural gas.

\section{Acknowledgments}

The authors gratefully acknowledge the support of Bosch Thermotechnologie for this program, which is also part of the ZEM-R project supported by FUI (Fonds Unique Interministériel). The authors also wish to thank David Charalampous and Erwann Pannier for their help and advises.

\section{Funding}

This work was supported by the Fonds Unique Interministériel [ZEM R].

\section{References}

Altendorfner, F., Kuhl, J., Zigan, L., and Leipertz, A. 2011. Study of the influence of electric fields on flames using planar LIF and PIV techniques. Proc. Combustion Inst., 33, 2, 3195-3201.

Alviso, D., Rolon, J., Scouflaire, P., and Darabiha, N. 2015. Experimental and numerical studies of biodiesel combustion mechanisms using a laminar counterflow spray premixed flame. Fuel., 153, 154-165.

Ballester, J., and García-Armingol, T. 2010. Diagnostic techniques for the monitoring and control of practical flames. Prog. Energy Combustion Sci., 36, 4, 375-411. 
Calcote, H. 1961. Ion production and recombination in flames. Symp (International) Comb., 8, 1, 184-199. Eighth Symposium (International) on Combustion.

Candel, S., Schmitt, T., and Darabiha, N. (2011). Progress in transcritical combustion: experimentation, modeling and simulation. Proceedings of 23rd ICDERS, Irvine USA, 27.

Cullen, R.E. 1950. The Effect of Pressure on the Propagation Rate of Bunsen Flames in Propane-Air and Ethylene-Air Mixtures, Willow Run Research Center, Engineering Research Institute, University of Michigan, Ann Arbor, MI.

Docquier, N., and Candel, S. 2002. Combustion control and sensors: a review. Prog. Energy Combustion Sci., 28, 2, 107-150.

Docquier, N., Lacas, F., and Candel, S. 2002. Closed-loop equivalence ratio control of premixed combustors using spectrally resolved chemiluminescence measurements. Proc. Combustion Inst., 29, 1, 139-145.

Fialkov, A.B. 1997. Investigations on ions in flames. Prog. Energy Combustion Sci., 23, 5, 399-528.

Franke, A. (2002). Characterization of an Electrical Sensor for Combustion Diagnostics. PhD thesis. Lund University.

García-Armingol, T., and Ballester, J. 2014a. Flame chemiluminescence in premixed combustion of hydrogen-enriched fuels. Int. J. Hydrogen Energy, 39, 21, 11299-11307.

García-Armingol, T., and Ballester, J. 2014b. Influence of fuel composition on chemiluminescence emission in premixed flames of $\mathrm{CH} 4 / \mathrm{CO} 2 / \mathrm{H} 2 / \mathrm{CO}$ blends. Int. J. Hydrogen Energy, 39, 35, 20255-20265.

Guiberti, T.F, Durox, D., Schuller, T. 2017. Flame chemiluminescence from CO2- and N2-diluted laminar $\mathrm{CH} 4 *$ air premixed flames, Combust. Flame, 181, 110-122. Beijing, China, July 19-22, 2015.

Higgins, B., McQuay, M., Lacas, F., and Candel, S. 2001a. An experimental study on the effect of pressure and strain rate on ch chemiluminescence of premixed fuel-lean methane/air flames. Fuel, 80, 11, 1583-1591.

Higgins, B., McQuay, M., Lacas, F., Rolon, J., Darabiha, N., and Candel, S. 2001b. Systematic measurements of $\mathrm{OH}$ chemiluminescence for fuel-lean, high-pressure, premixed, laminar flames. Fuel, 80, 1, 67-74.

Hurle, I.R., Price, R.B., Sugden, T.M., and Thomas, A. 1968. Sound emission from open turbulent premixed flames. Proc. Royal Soc. London A: Math. Phys. Eng. Sci., 303, 1475, 409-427.

Karrer, M., Bellenoue, M., Labuda, S., Sotton, J., and Makarov, M. 2010. Electrical probe diagnostics for the laminar flame quenching distance. Exp. Thermal Fluid Sci., 34, 2, 131-141.

Kedia, K.S. (2010). Numerical simulations of perforated plate stabilized premixed flames with detailed chemistry. PhD thesis. Massachusetts Institute of Technology.

Kiefer, M., Maas, U., Park, S., Pian, X., Köllmann, G., Loohuis, G.O., Leerkes, D., Kalk, H., Markus, D., and Langer, T. (2012). Combustion control based on flame ionization. In 25th World Gas Conference Kuala Lumpur, Malaysia. June 04-08, 2012.

Kojima, J., Ikeda, Y., and Nakajima, T. 2000. Spatially resolved measurement of $\mathrm{OH}^{\star}, \mathrm{CH}^{\star}$, and $\mathrm{C2}^{\star}$ chemiluminescence in the reaction zone of laminar methane/air premixed flames. Proc. Combustion Inst., 28, 2, 1757-1764.

Kojima, J., Ikeda, Y., and Nakajima, T. 2005. Basic aspects of $\mathrm{OH}(\mathrm{A}), \mathrm{CH}(\mathrm{A})$, and C2(d) chemiluminescence in the reaction zone of laminar methane-air premixed flames. Combust. Flame, 140, $1,34-45$.

Lee, J., and Santavicca, D. 2003. Experimental diagnostics for the study of combustion instabilities in lean premixed combustors. J. Prop. Power, 19, 5, 735-750.

Lewis, B., and Von Elbe, G. 1987. CHAPTER V - Combustion waves in laminar flow. Combustion, Flames and Explosions of Gases, 3rd ed. 215-417. Academic Press

Näslund, M. (2014). Combustion control in domestic gas appliances - fuel gases containing hydrogen. Technical report, Danish Gas Technology Centre.

Orain, M., and Hardalupas, Y. 2010. Effect of fuel type on equivalence ratio measurements using chemiluminescence in premixed flames. Comptes Rendus Mecanique, 338, 5, 241-254. 
Qin, Z., Lissianski, V.V., Yang, H., Gardiner, W.C., Davis, S.G., and Wang, H. 2000. Combustion chemistry of propane: A case study of detailed reaction mechanism optimization. Proc. Combustion Inst., 28, 2, 1663-1669.

Rodrigues, J.M. (2005). Analyse de la répartition du potentiel et des charges dans une flamme polarisée. Corrélation avec la distance d'extinction. $\mathrm{PhD}$ thesis. Université de Rouen.

Samaniego, J.-M., Egolfopoulos, F., and Bowman, C. 1995. CO2* chemiluminescence in premixed flames. Combustion Sci. Technol., 109, 1-6, 183-203.

Smith, G.P., Golden, D.M., Frenklach, M., Eiteener, B., Goldenberg, M., Bowman, C.T., Hanson, R. K., Gardiner, W.C., Lissianski, V.V., and Qin, Z.W. (2000). GRI-Mech 3.0. http://www.me. berkeley.edu/gri_mech/

Smith, G.P., Luque, J., Park, C., Jeffries, J.B., and Crosley, D.R. 2002. Low pressure flame determinations of rate constants for $\mathrm{OH}(\mathrm{A})$ and $\mathrm{CH}(\mathrm{A})$ chemiluminescence. Combust. Flame, 131, 1-2, 59-69.

Williams, T., Bryant, N., Brown, M., Eastell, L., Jones, A., Kane, A., Paxton, A., Davies, G., Morris, A., Cox, D.J., Wyatt, J., Da Costa, M., Fidanboy, S., Austin, N., and Daut, S. (2012). Gas quality harmonization cost benefit analysis. Technical report, GL Noble Denton and Pöyry Management Consulting. 